\title{
Role of candidate genes in regulation of embryonic survival and maternal recognition of pregnancy in farm animals
}

\author{
Rohit Kumar ${ }^{1 \ltimes 2}$, P. W. Ramteke ${ }^{1}$, Amar Nath $^{3}$ and Satyendra P. Singh ${ }^{4}$
}

1. Department of Biological Sciences, Sam Higginbottom Institute of Agriculture, Technology \& Sciences (SHIATS), Allahabad (UP), India; 2. Animal Genetics Division, Indian Veterinary Research Institute, Izatnagar, Bareilly (UP), India 3. Division of surgery, Indian Veterinary Research Institute, Izatnagar, Bareilly (UP), India; 4. Department of Animal Genetics and Breeding, College of Veterinary and Animal Science, DUVASU, Mathura (UP), India

Corresponding author:Rohit Kumar, email:rohit2005biotec@gmail.com

Received: 30-08-2012, Accepted: 02-10-2012, Published online: 06-02-2013

How to cite this article: Kumar R, Ramteke PW, Nath A and Singh SP (2013) Role of candidate genes in regulation of embryonic survival and maternal recognition of pregnancy in farm animals, Vet. World 6(5): 280-284, doi: 10.5455/vetworld. 2013.280-284

\begin{abstract}
Successful growth and development of the post-hatching blastocyst and pregnancy establishment are results of the interaction between a competent embryo and a receptive uterine environment. There are certain marker gene transcripts identified which contribute and regulate the bidirectional channel of communication during the pregnancy period in farm animals. The changes in temporal gene expression in the endometrium are similar in pregnant and cyclic animals up to the time of maternal recognition of pregnancy (MRP) when conceptus derived factors affect expression of a large number of genes in pregnant animals. In this review we have discussed a set of candidate genes expressed or induced for MRP. There are certain genes playing important role in MRP in farm animals, of which interferon-tau (IFNT), Ubiquitin Cross Reative Protein (UCRP), Ghrelin, Aldoketoreductase-1B5 (AKR1B5), SERPINA14 are having esteemed role in farm animals. These genes appear to have role in successful establishment of pregnancy and expression of the cascade of signalling molecules. However, IFNT was recognized as one of the earliest expressing gene specifically required for maintenance of pregnancy.
\end{abstract}

Keywords: AKR1B5, ghrelin, interferan tau, maternal recognition of pregnancy, SERPINA14

\section{I ntroduction}

Successful embryo development and survival includes formation of blastocyst, implantation into the uterus, formation of placenta and development of the heart and vascularisation of both embryo and fetus to assist nutrient deliverance [1]. Among these developmental events, implantation of embryo is a crucial step and its success mostly dependent on the efficiency with which the MRP is established [2]. The MRP includes series of events that are synchronized by the endocrine interaction between the dam and the embryo. Survivability and development of the embryo is influenced directly and indirectly by exogenous and endogenous factors. Out of these factors, candidate genes influence molecular interactions involved in maintenance of pregnancy through reciprocal interactions between the conceptus and endometrium.

The majority of studies examining the molecular mechanisms of conceptus-endometrial interactions were carried out during the peri-implantation period of pregnancy and described changes in the transcriptome of the endometrium [3,4]. Recent studies [4] indicated that the major factor affecting gene expression in the endometrium is day of the estrous cycle/early pregnancy. In other words, irrespective of pregnancy status, the temporal changes in gene expression in the endometrium are similar in pregnant and cyclic animals up to the time of maternal recognition of pregnancy when conceptus-derived factors, such as Interferon tau (IFNT), induces or further amplifies expression of a large number of genes in pregnant animals.
A transcriptome analysis in the cattle endometrium revealed that Ubiquitin Cross Reative Protein (UCRP) is one of the differentially expressed genes which up-regulates in response to conceptus derived IFNT. UCRP is an ubiquitin homolog that is expressed transiently in the uterus during early pregnancy in several species including cattle [5], sheep [6], pigs [7] and horse [8]. The UCRP has an important role in the degradation of the cytosolic uterine proteins (e.g. receptors, enzymes and transcription factors of regulating genes) that are detrimental for fetal/embryo survival. It ligates and alters the proteosomal degradation of cytosolic uterine proteins that are involved in uterine PGF2 $\alpha$ release [9]. Consequently, it is postulated that the expression of the UCRP is a conserved uterine response to the embryo and are hypothesized to play important biological roles uterine receptivity and conceptus implantation [10]. However Uterine serpins (SERPINA 14) is secreted from the uterine endometrium mainly under the influence of progesterone in many ungulate animal species including cattle [11], sheep [12], goat [13] and pig [14]. The SERPINA14 protein performs diverse biological functions which include direct nutrition to the conceptus, growth control, inhibition of proteolytic activities and suppression of the local maternal immune system for sustaining pregnancy.

The opportunity of successful development of an embryo depends on genetic factors of both the embryo and the mother's endometrium. Anumber of genes have been identified that become active after appearance 
and towards implantation of the embryo in the uterus viz. IFNT, UCRP, Ghrelin, Aldoketoreductase -1B5 (AKR1B5), SERPINA14. These candidate genes regulate the endometrial environment to establish pregnancy in farm animals. In this review we summarize the current information on the biology of above genes for establishment and maintenance of pregnancy, particularly on farm animals.

\section{I nterferon tau (I FNT)}

IFNT, a member of the type I interferon family, is secreted by the trophectoderm of the elongating blastocyst and acts as a primary signal for MRP. IFNT is encoded by a cluster of genes $[15,16]$ which have been evolved from an ancestral IFN-omega gene that acquired a trophectoderm-specific promoter shortly after divergence of pecoran ruminants (cattle, sheep, goats, musk oxen, gazelles, giraffes and deer) from other artiodactyls [17]. Although non-ruminant mammals do not produce an IFN that controls maternal recognition of pregnancy, IFNs are expressed by placental tissues in various mammals. In ruminant ungulates, such as cattle, sheep and goats, IFNT is essential for the maintenance of pregnancy [18]. IFNT acts on the endometrium to abrogate the endometrial luteolytic mechanism by either inhibiting the transcription of estrogens and/ or oxytocin receptors [19].

It is expressed constitutively by the trophectoderm from the period of blastocyst formation until attachment of the elongated conceptus to the uterine wall [16]. IFNT is the initial requisite signal for pregnancy recognition in ruminants [20]. Systemic or intrauterine treatment with either native or recombinant ovine or bovine IFN- induces a brief pseudo pregnant condition that lasts from a few days to several weeks in sheep, cattle and goats [21-23].

Till now, several polymorphic/allelic variants of IFN have been reported in ovine, bovine, bubaline and different breeds of caprine from livestock species. However, possibility of existence of the additional allelic variants in the caprine and bubaline genome and their functional role is yet to be explored.

\section{Ubiquitin cross reative protein (UCRP)}

UCRP is a member of ubiquitin-like (UBL) protein super family, plays an important role for foetal or embryo survival through establishment and maintenance of pregnancy in ruminant ungulates. It functions in response to conceptus derived IFNT by the proteasomal degradation of cytosolic uterine proteins that are involved in uterine PGF2 release.

The UCRP gene has been implicated as one of the key players in determining the reproductive efficiency in farm animal species. IFNT up-regulates many interferon stimulated genes (ISGs) viz., interferonstimulated gene-17 (ISG17) in bovine [24] and ovine species [25] and its homologs ISG15 in human and murine [26,27]. The ISG15/17 gene shares limited $(\sim 30 \%)$ amino acid sequence identity with a tandem ubiquitin repeat [24,26] Thus, both these proteins are also called as ubiquitin cross-reactive protein.

\section{Ghrelin}

Ghrelin is a novel motilin related endogenous ligand for growth hormone secretagouge receptor. It involves in various biological functions including regulation of female reproduction, but the presence of ghrelin and its role in reproductive functions in goat is not known. It acts as an endogenous ligand for growth hormone secretagouge (GHS) receptor, involved in several biological functions including the $\mathrm{GH}$ releasing activity [28] and carbohydrate metabolism [29]. In addition, ghrelin has also been implicated as a crucial factor affecting female reproduction [30]. Ghrelin has been shown to regulate several reproductive functions including embryo implantation [31] and modulating reproductive hormone secretion [32-34]. Ghrelin is expressed in different parts of reproductive tract including the uterus, placenta, ovary and testis [35-37].

Expression of ghrelin mRNA has been found to be increased in early pregnant endometrial tissue compared to proliferative or secretary phase of endometrial tissue in human [31]. Uterine endometrial tissue is the maternal interface of fetal-maternal interaction and various locally produced factors regulate the embryo receptivity of endometrium [38]. It has been demonstrated the involvement of ghrelin in remodeling or decidualization of human uterine endometrium [35]. Low level of ghrelin expression in human endometrial tissues is associated with decreased fertility [39]. Amongst several factors secreted by the endometrium, ghrelin has been established as one of the factors influencing fertility in recent studies $[39,40]$. However, there is no report about the presence of ghrelin and its expression in reproductive organs of goat and buffalo.

\section{Aldoketoreductase - 1B5 (AKR1B5)}

AKR1B5 a member of Aldoketoreductse (AKR) family, with prostaglandin F synthase (PGFS) activity, is associated with prostaglandins (PGs) biosynthesis. PGs are important regulators of female reproductive functions viz., ovulation, uterine receptivity, implantation and parturition [41]. Among the different classes of PGs, PGF2 $\alpha$ - one of main prostanoids produced by bovine endometrium [42]. In ruminants, it regulates ovarian cycle by initiating the regression (luteolysis) of corpus luteum and functions as a major luteolytic agent [43].

PGs are synthesized from arachidonic acid and converted to $\mathrm{PGH} 2$ by either of two isoforms of $\mathrm{PGH}$ synthase (PGHS), the constitutive cyclooxygenase (COX)-1 or the inducible COX-2. PGH2 is the common precursor of all PGs generated by specific terminal synthases such as PGF synthase (PGFS) for PGF2 $\alpha$ and PGE2 [44]. PGF2 $\alpha$ is a bioactive lipid belonging to the eicosanoid family. Its biosynthesis occurs via reduction of $\mathrm{PGH} 2$ by a 9,11-endoperoxyde reductase. Till now several PGFS have been identified, from cow $[45,46]$, human [47], sheep [48], Trypanosoma brucei [49] and porcine endometrium [50]. All mammalian 
PGFS belong to Aldoketoreductase $1 \mathrm{C}$ (AKR1C) family, with hydroxylsteroid dehydrogenase (HSD) activity. However, none of known functional PGFS from AKR1C family was detected in bovine endometrium, while the expression of PGF $2 \alpha$ was very high [42]. So. It was hypothesized that AKR1B5, recently renamed as Bos taurus AKR1B1 was the factor, responsible for the release of huge amount of PGF $2 \alpha$ in bovine endometrium [42]. Due to its $20 \alpha$ HSD activity, AKR1B5 (share $86 \%$ homology with AKR1B1 in human) is responsible for the release of PGF $2 \alpha$ and inactivate progesterone to regulate endometrial function in bovine endometrium $[51,52]$.

\section{SERPI NA 14}

Uterine serpins (SERPINA14), a member of serpin super family of serine protease inhibitors [53], are secreted from the uterine endometrium mainly under the influence of progesterone in many ungulate animal species including bovine [11], ovine [12,13] and porcine [14]. The SERPINA14 protein performs diverse biological functions which include direct nutrition to the conceptus, growth control, inhibition of proteolytic activities and suppression of the local maternal immune system for sustaining pregnancy. Ovine SERPINA14 is known to inhibit lymphocyte proliferation [54]. The ability of ovine SERPINA14 to bind with the members of the pregnancy associated glycoproteins [11], aspartic proteinases [54] and to the growth factor, activin suggests its role as a carrier protein during gestation. Recently, SERPINA14 has been further implicated as one of the important (GE) during days $13-15$ of the estrus cycle as well as during days 15-50 of pregnancy in sheep [55] and on day 25 of pregnancy in goat [13]. In bovine, SERPINA14 is reported to be expressed predominantly in the uterine endometrium during pregnancy [56].

\section{Conclusion}

The present review summarises the role of important candidate genes regulating estrus cycle, maternal recognition of pregnancy and embryo survivability in farm animals. These genes predominantly appear to have role in successful establishment of pregnancy and directly or indirectly regulated the expression of the cascade of signalling molecules to establish reproductive cycle. IFNT was specifically being considered as one of the earliest expressing gene required for the maintenance of successful pregnancy. Reproductive efficiency, survivability and development of the embryo is influenced directly and indirectly by exogenous and endogenous factors. Out of these factors, candidate genes influence molecular interactions involved in maintenance of pregnancy through reciprocal interactions between the conceptus and endometrium. The conceptus derived IFNT was also responsible for the proper functioning of UCRP. Ghrelin was found to be responsible for several reproductive fuctions mainly in embryo implantation
[31] and modulating reproductive hormone secretion $[32,33]$. Besides Ghrelin and AKR1B5 which regulates endometrial function, the SERPINA14 protein performs diverse biological functions which included direct nutrition to the conceptus, growth control, inhibition of proteolytic activities and suppression of the local maternal immune system for sustaining pregnancy. The functional role of these genes for establishment of pregnancy is yet to be explored in different domestic species. Further, studies on these genes can improve the reproductive efficiency, establishment and maintenance of pregnancy in farm animals. Apart from above, these gene can also be established as a competent marker to improve breed with reproductive health though selective breeding strategy.

\section{Acknowledgements}

Authors would like to thank Vice Chancellor, Sam Higginbottom Institute of Agriculture, Technology \& Sciences (SHIATS) Allahabad, (UP), India.

\section{References}

1. Cross J.C., Lu y., Hemberger M., Adamson L. (2001) Invasion of mouse uterus by distinct trophoblast subtypes. Placen., 22 (7): 64.

2. Claudia Klein and Mats H.T.Troedsson (2011) Transcriptional Profiling of Equine Conceptuses Reveals New Aspects of Embryo-Maternal Communication in the Horse. Biol. Reprod., DOI:10.1095/biolreprod.110.088732.

3. Solomon Mamo, Jai P. Mehta, Paul McGettigan, Trudee Fair, Thomas E. Spencer, Fuller W. Bazer, and Patrick Lonergan (2011) RNA Sequencing Reveals Novel Gene Clusters in Bovine Conceptuses Associated with Maternal Recognition of Pregnancy and Implantation. Biol. Reprod., 85(6):114351.

4. Forde N., Carter F., Fair T., Crowe M.A., Evans A.C., Spencer T.E., Bazer F.W., McBride R., Boland M.P., O'Gaora P., Lonergan P., Roche J.F. (2009) Progesterone- regulated changes in endometrial gene expression contribute to advanced conceptus development in cattle. Biol. Reprod., 81: 784- 794 .

5. Johnson G.A., Austin K.J., Collins A.M., Murdoch W.J., Hansen T.R. (1999) Endometrial ISG17 mRNA and a related mRNA are induced by interferon- $t$ and localized to glandular epithelial and stromal cells from pregnant cows. Endocri.., 10: 243-252.

6. Johnson G. A., Austin K. J., Kirk A. V., Spencer T. E., Burghardt R. C., Hansen T. R. and Bazer W. F. (1999) Expression of the Interferon tau InducibleUbiquitin CrossReactive Protein in the Ovine Uterus. Biol. Reprod., 61: 321318 .

7. Joyce M.M., Burghardt R.C., Bazer F.W., Zaunbrecher G.M., Johnson G.A. (2003) Interferon-stimulated genes (ISGs) are induced in the endometrium of pregnant but not pseudopregnant pigs. Biol. Reprod., 68( 1): 230.

8. Klein C., Scoggin K.E., Troedsson M.H. (2011) The expression of 685 interferon-stimulated gene 15 in equine endometrium. Reprod. Domest. Anim., 46: 692-698. 687.

9. Hansen T. R., Austin K. J. and Johnson G. A. (1997) Transient ubiquitin cross-reactive protein gene expression in the bovine endometrium. Endocrinol., 138: 5079-5082.

10. Spencer T.E., Sandra O., Wolf E. (2008) Genes involved in conceptus-endometrial interactions in ruminants: insights from reductionism and thoughts on holistic approaches. Reprod., 135:165-179.

11. Mathialagan N., Hansen T.R. (1996) Pepsin-inhibitory activity of the uterine serpins. Proc. Nat. Acad. Sci. USA, 93: 
13653-13658.

12. Ing N.H., Francis H., McDonnell J.J., Amann J.F., Roberts R.M. (1989) Progesterone induction of the uterine milk proteins: major secretory proteins of sheep endometrium. Biol.Reprod., 41: 643-654.

13. Tekin S., Padua M.B., Newton G.R., Hansen P.J. (2005) Identification and cloning of caprine uterine serpin. Mol. Reprod.Dev., 70: 262-270.

14. Malathy P.V., Imakawa K., Simmen R.C., Roberts R.M. (1990) Molecular cloning of the uteroferrin associated protein, a major progesterone-induced serpin secreted by the porcine uterus, and the expression of its mRNA during pregnancy. Mol. Endocrinol., 4: 428-440.

15. Angela M. W., and R Michael R. (2009) Characterization of the bovine type I IFN locus: rearrangements, expansions, and novel subfamilies. BMC Gen., 24(10) :187.

16. Ealy A.D., Larson S.F., Liu L., Alexenko A.P., Winkelman G.L., Kubisch H.M. (2001) Polymorphic forms ofexpressed bovine interferon-tau genes: relative transcript abundance during early placental development,promoter sequences of genes and biological activity of protein products. Endocrinol., 142: 2906-15.

17. Jennifer L. F., (2008) Biological functions of galectin 15 (LGALS15) in the ovine uterus, Tex. A\&M Univ., page 8 (http://gradworks.umi.com/33/47/3347916.html). Retrieved on 04-08-2012.

18. Fuller W. B., Gwonhwa S. and William W. T. (2012) Roles of Conceptus Secretory Proteins in Establishment and Maintenance of Pregnancy in Ruminants, Asian-Aust. J. Anim. Sci., 25: 1-16.

19. Alfredo Q. A., Brett T. W. , Jared J. R., Natalia P. S. , Gordon D. N. , Fuller W. B., and Thomas R. H. (2011) Endocrine Delivery of Interferon-tau into the Uterine or Jugular Veins at Different Concentrations Protects the Corpus Luteum from Prostaglandin F2 Alpha Induced Luteolysis. Biol. Reprod., $85: 227$.

20. Rebecca M. S., David W. E., Jinyoung K., Robert C. B., Fuller W. B., Greg A. J. and Thomas E. S. (2009) InsulinLike Growth Factor Binding Protein-1 in the Ruminant Uterus: Potential Endometrial Marker and Regulator of Conceptus Elongation, Endocrinol., 150 (9): 4295.

21. Kiesling D.O., Stewart A.N., Ealy A.D. (2000) Single daily intramuscular injections of low quantities of recombinant ovine interferon-tau extends luteal life-span in Angora goats. J. Anim. Sci., 78: 2966-71.

22. Newton G.R., Ott T.L., Woldesenbet S., Shelton A.H., Bazer F.W. (1996) Biochemical and immunological properties of related small ruminant trophoblast interferons. Theriogenol., 46:703-16.

23. Winkelman G.L., Roberts R.M., James P.A., Alexenko A.P., Ealy A.D. (1999) Identification of the expressed forms of ovine interferon-tau in the periimplantation conceptus: sequence relationships and comparative biological activities. Biol. Reprod., 61:1592-600.

24. Perry D. J., Austin K. J. and Hansen T. R. (1999) Cloning of IFN-stimulated gene 17: the promoter and nuclear proteins that regulates transcription. Mol. Endocrinol., 13: 11971206.

25. Joyce M.M., White F.J., Burghardt R.C., Muniz J.J., Spencer T.E., Bazer F.W., Johnson G.A. (2005) Interferon stimulated gene 15 conjugates to endometrial cytosolic proteins and is expressed at the uterine-placental interface throughout pregnancy in sheep. Endocrinol., 146: 675-684.

26. Reich N., Evans D., Levy D., Fahey D., Knight Jr E., Darnell Jr. JE. (1987) Interferon-induced transcription of a gene encoding a $15-\mathrm{kDa}$ protein depends on an upstream enhancer element. Proc. Nat. Acad. Sci. USA, 84: 6394-6398.

27. Loeb K.R. and Haas A.L. (1992) The interferon-inducible $15-\mathrm{kDa}$ ubiquitin homolog conjugates to intracellular proteins. J. Biol. Chem., 267: 7806-7813.

28. Joëlle D., Virginie M., Stéphanie C. C., Christelle R., and P.
F., (2010) Ghrelin in Female and Male Reproduction, (doi:10.1155/2010/158102).

29. Cruz S.A., Tseng Y.C., Kaiya H., Hwang P. P. (2010) Ghrelin affects carbohydrate-glycogen metabolism via insulin inhibition and glucagon stimulation in the zebrafish (Danio rerio) brain, Comp. Biochem. Physiol. A. Mol. Integr. Physiol., 156(2):190-200.

30. J. Ryan M., Sarah B. L., James Mc., Marya S., Tamas L. H., and Hugh S. T., (2011) Maternal Ghrelin Deficiency Compromises Reproduction in Female Progeny through Altered Uterine Developmental Programming. Endocrinol., 152(5): 2060-2066.

31. Repaci, A., Gambineri, A., Pagotto, U., Pasquali, R. (2010) Ghrelin and reproductive disorders, Mol. Cel. Endocrinolo., doi:10.1016/j.mce.2011.02.022.

32. Viani I., Vottero A., Tassi F., Cremonini G., Sartori C., Bernasconi S., Ferrari B., Ghizzoni L. (2008) Ghrelin inhibits steroid biosynthesis by cultured granulosa-lutein cells. J. Clin. Endo. Met., 93:1476-1481.

33. Lebrethon M.C., Aganina A., Fournier M., Gerard A., Parent A.S., Bourguignon J.P. (2007) Effects of in vivo and in vitro administration of ghrelin, leptin and neuropeptide mediators on pulsatile gonadotrophin-releasing hormone secretion from male rat hypothalamus before and after puberty. $J$. Neuroendocrinol., 19:181-188.

34. Vulliemoz N.R., Xiao E., Xia-Zhang L., Germond M., Rivier J., Ferin M. (2004) Decrease in luteinizing hormone pulse frequency during a five-hour peripheral ghrelin infusion in the ovariectomized rhesus monkey. J. Clin. Endocrinol. and Met., 89:5718-5723.

35. Tawadros N., Salamonsen L.A., Dimitriadis E., Chen C. (2007) Facilitation of decidualization by locally produced ghrelin in the human endometrium. Mol. H. Reprod., 13:483489.

36. Caminos J.E., Tena-Sempere M., Gaytan F., Sanchez-Criado J.E., Barreiro M.L., Nogueiras R., Casanueva F.F., Aguilar E., Dieguez C. (2003) Expression of ghrelin in the cyclic and pregnant rat ovary. Endocrinol., 144:1594-1602.

37. Barreiro M.L., Gaytan F., Caminos J.E., Pinilla L., Casanueva F.F., Aguilar E., Dieguez C., Tena-Sempere M. (2002) Cellular location and hormonal regulation of ghrelin expression in rat testis. Biol. Reprod., 67:1768-1776.

38. Singh M., Parvesh C. And Eric A., (2011) Bridging endometrial receptivity and implantation: network of hormones, cytokines, and growth factors, J. Endocrinol., 210:5-14.

39. Aghajanova L., Rumman A., Altmae S., Wanggren K., Stavreus-Evers A. (2010) Diminished endometrial expression of ghrelin and ghrelin receptor contributes to infertility. Reprod. Sci., 17:823-832.

40. Martin J.R., Lieber S.B., McGrath J., Shanabrough M., Horvath T.L., Taylor H.S. (2011) Maternal ghrelin deficiency compromises reproduction in female progeny through altered uterine developmental programming. Endocrinol., 152:2060-2066.

41. Lindstrom T. and Bennett P. (2004) Transcriptional regulation of genes for enzymes of the prostaglandin biosynthetic pathway. Prostag. Leukot. Essent. Fat. Acid.;70(2): 115-135.

42. Madore E., Harvey N., Parent J., Chapdelaine P., Arosh J.A., Fortier M.A. (2003) An aldose reductase with 20 alphahydroxysteroid dehydrogenase activity is most likely the enzyme responsible for the production of prostaglandin $\mathrm{f} 2$ alpha in the bovine endometrium. J. Biol. Chem., 278(13): 11205-11212.

43. Arosh J.A., Banu S.K., Chapdelaine P., Madore E., Sirois J., Fortier M.A. (2004) Prostaglandin biosynthesis, transport, and signaling in corpus luteum: a basis for autoregulation of luteal function. Endocrinol.; 145(5): 2551-2560.

44. Bresson E., Boucher-Kovalik S., Chapdelaine P., Madore E., Harvey N., Laberge P. Y., Leboeuf M., and Fortier M.A. (2011) The Human Aldose Reductase AKR1B1 Qualifies as the Primary Prostaglandin F Synthase in the Endometrium, $J$. 
Clin. Endocrinol. Metab., 96(1): 210-219.

45. Suzuki T., Fujii Y., Miyano M., Chen L.Y., Takahashi T., Watanabe K. (1999) cDNA cloning, expression, and mutagenesis study of liver-type prostaglandin F synthase. $J$. Biol. Chem., 274(1): 241-248.

46. Chen L.Y., Watanabe K., Hayaishi O. (1992) Purification and characterization of prostaglandin $\mathrm{F}$ synthase from bovine liver. Arch. Biochem. Biophys., 296(1): 17-26.

47. Suzuki-Yamamoto T., Nishizawa M., Fukui M., OkudaAshitaka E., Nakajima T., Ito S. (1999) cDNA cloning, expression and characterization of human prostaglandin $\mathrm{F}$ synthase. FEBS Lett., 462(3): 335-340.

48. Wu W.X., Ma X.H., Yoshizato T., Shinozuka N., Nathanielsz P.W. (2001) Increase in prostaglandin H synthase 2, but not prostaglandin F2alpha synthase mRNA in intrauterine tissues during betamethasone-induced premature labor and spontaneous term labor in sheep. J. Soc. Gynecol. Investig., 8(2): 69-76.

49. Kubata B.K., Duszenko M., Kabututu Z., Rawer M., Szallies A., Fujimori K. (2000) Identification of a novel prostaglandin $\mathrm{f}$ (2alpha) synthase in Trypanosoma brucei. $J$. Exp.Med., 192(9): 1327-1338.

50. Waclawik A., Rivero-Muller A., Blitek A., Kaczmarek M.M., Brokken L.J., Watanabe K. (2006) Molecular cloning and spatiotemporal expression of prostaglandin $\mathrm{F}$ synthase and microsomal prostaglandin $\mathrm{E}$ synthase-1 in porcine endometrium. Endocrinol., 147(1): 210-221.

51. Frontier M.A. , K. Krishnaswamy, G. Danyod, S. Boucher-
Kovalik, P. Chapdelaine J.A. (2008) Apostgenomic integrated view of prostaglandins in reproduction: implications for other body systems. J. physiol. pharmacol., 59: 65-89.

52. Kabututu Z., Manin M., Pointud J.C., Maruyama T., Nagata N., Lambert S., Lefrancois-Martinez A.M., Martinez A., Urade Y. (2009) Prostaglandin F2alpha synthase activities of aldo-keto reductase 1B1, 1B3 and 1B7. J. Biochem., 145: 161-168.

53. Maria B. P., Andrés A. K., Miryan Y. C., and Peter J. H., (2009) The molecular phylogeny of uterine serpins and its relationship to evolution of placentation, FASEB Jour. (doi: 10.1096/fj.09-138453).

54. Susanne E. U., Thomas F., Katy S., Eva E., Nadine W., Georg J. A., Horst-Dieter R., Myriam R., Eckhard W., Heinrich H.D. M. and Stefan B. (2009) Evidence for Estrogen Dependent Uterine Serpin (SERPINA14) Expression During Estrus in the Bovine Endometrial Glandular Epithelium and Lumen. Biol. Reprod., 81, 4: 795-805.

55. Stewart M.D., Johnson G.A., Gray C.A., Burghardt R.C., Schuler L.A., Joyce M.M., Bazer F.W., Spencer T.E. (2000) Prolactin receptor and uterine milk protein expression in the ovine endometrium during the estrous cycle and pregnancy. Biol. Reprod., 62: 1779-1789.

56. Khatib H., Schutzkus V., Chang Y.M., Rosa G.J. (2007) Pattern of expression of the uterine milk protein gene and its association with productive life in dairy cattle. J. Dairy. Sci., 90: 2427-2433.

$* * * * * * * *$ 